\title{
Effects of chlordiazepoxide on odor-induced risk assessment behaviors in mice
}

\author{
COLLEEN M. GARBE, ERNEST D. KEMBLE, and PIA C. STRUNK \\ University of Minnesota, Morris, Minnesota
}

\begin{abstract}
The effects of treatment with three chlordiazepoxide (CDP) doses $(2.0,8.0$, and $12.0 \mathrm{mg} / \mathrm{kg}$ ) on risk assessment behaviors evoked by a novel odor were investigated. Both the frequency and duration of flatback approaches and stretch attends were strongly suppressed at the highest CDP dose. It is suggested that CDP alters normal olfactory function only at doses that attenuate offensive attack, but that CDP-induced reductions in defensive behaviors, seen at lower doses, are probably not importantly mediated by disrupted olfaction.
\end{abstract}

Chlordiazepoxide (CDP) and related benzodiazepine compounds consistently reduce defensive or anxious behaviors among both wild and laboratory rodents (e.g., Blanchard \& Blanchard, 1990; Blanchard, Blanchard, \& Rodgers, 1990; Blanchard, Hori, Rodgers, Hendrie, \& Blanchard, 1989; File, 1990; Krsiak \& Sulcova, 1990), and sometimes (e.g., Krsiak, 1979; Panksepp, 1971), but not always (e.g., Miczek, 1974; Rodgers \& Waters, 1985) inhibit conspecific attack. These antiaggressive actions are frequently accompanied by increased social investigatory behaviors, consisting largely of conspecific sniffing (e.g., Krsiak, 1979; Poole, 1973). The latter finding suggests that disruptions in normal olfactory function may be an important mediator of CDP's behavioral effects (e.g., Dixon, 1982). Although several other drugs do indeed both suppress conspecific attack and alter olfactory preferences (e.g., Kemble, Behrens, Rawleigh, \& Gibson, 1991; Kemble, Schultz, \& Thornton, 1986; Ostrem, Rawleigh, \& Kemble, 1992; Soffie \& Lamberty, 1988), CDP was not found to alter preference for conspecific odors or rejection of novel odors in a recent study (Garbe, Rawleigh, Kemble, \& Bursell, in press). Subsequent research, however, suggested that olfactory preference may be rather insensitive to variations in the emotionprovoking properties of odors. When confronted by the odors of familiar antagonists (Garbe \& Kemble, 1993), subordinate mice display species-typical risk assessment behaviors (flatback approaches, stretched attention postures, or stretch attends, and immobility), which are quite similar to those evoked by predatory odors (Blanchard, Blanchard, Weiss, \& Meyer, 1990). These responses are virtually absent among dominant mice exposed to subordinate odors. Despite the marked differences in risk assessment by dominant and subordinate males, however, both groups showed comparable levels of approach

This research was partially supported by an Undergraduate Research Opportunities Program grant to C. M. G. Please address reprint requests to E. Kemble, Division of Social Sciences, University of MinnesotaMorris, Morris, MN 56267. to, and contact with, the conspecific odorants. Thus, similar levels of approaches to (and apparent preference for) odors during preference testing may result from strikingly different emotional/motivational states. Direct observation of risk assessment would therefore seem to offer a more unambiguous index of CDP's possible effects on odorinduced fear. The present experiment provided such data.

\section{METHOD}

\begin{abstract}
Subjects
The subjects were 39 experimentally naive male CD-1 mice weighing 35.1-45.9 g. The mice were individually housed in $20.5 \times 26.0$ $\times 41.0 \mathrm{~cm}$ glass aquaria on $650 \mathrm{ml}$ of sawdust bedding for 6 days prior to testing. All the subjects had ad-lib access to Purina Lab Chow and water throughout the experiment and were maintained on a 12:12-h light:dark cycle. All testing was conducted in the home aquaria during the light cycle and behaviors were recorded by videocamera. All the mice were habituated to placement under the videocamera for $5 \mathrm{~min} /$ day for 5 consecutive days.
\end{abstract}

\section{Odor Source}

Odors were provided by $1.0 \mathrm{~g}$ of untreated sheep wool, which was clipped from donors and stored in sealed containers at $-5^{\circ} \mathrm{C}$ until immediately before its use as a stimulus. Selection of this odor was based on previous data (Garbe, Kemble, \& Rawleigh, in press), which revealed that cat fur and sheep wool evoked virtually identical patterns of risk assessment behaviors.

\section{Procedure}

On the day of testing, the subjects were randomly assigned to weightbalanced groups designated to receive $2.0,8.0$, or $12.0 \mathrm{mg} / \mathrm{kg}$ doses of CDP by intraperitoneal injection $(n s=10)$ or an equivalent volume of isotonic saline $(n=9) 30 \mathrm{~min}$ prior to testing. The CDP doses were well within the range known to effectively reduce defensive behavior (e.g., Blanchard et al., 1989; Rodgers \& Waters, 1985). Immediately prior to drug or saline injection, food and water containers were removed from the aquaria although food embedded in the sawdust substrate (5-10 pieces per aquarium) was left undisturbed. The aquarium was then covered with a sheet of clear Plexiglas for videotaping. Next, the wool was scattered evenly across the half of the aquarium most distal to the mouse. Risk assessment behaviors (flatback approach and stretched attention postures) and appetitive behaviors (rearing, grooming, eating) were then recorded for $10 \mathrm{~min}$. In addition, the number of entries into, and time spent in, the odorous half of the aquarium was recorded. Because some behaviors were totally absent among a substantial number of mice, Kruskal-Wallis tests were employed for overall analyses and Mann-Whitney $U$ tests were utilized for individual comparisons. 


\section{RESULTS}

The frequency and duration of flatback approaches and stretch attends are depicted in Figure 1. There were significant overall drug-induced decreases in the frequency $(H=11.12, p<.05)$ and duration $(H=14.31, p<$ $.01)$ of flatback approaches. There was also a significant overall reduction in stretch attend frequency $(H=11.17$, $p<.05$ ) and a marginally significant reduction in duration $(H=7.27, p<.10)$. These overall effects were almost entirely accounted for by the striking reductions in both flatback approaches and stretch attends at the highest dose of CDP. The frequencies and durations of flatback approach at the $12.0 \mathrm{mg} / \mathrm{kg}$ dose differed significantly from all other groups $(p \mathrm{~s}<.05-.005)$. The $2.0 \mathrm{mg} / \mathrm{kg}$ dose also produced a marginally significant reduction in flatback duration $(p<.10)$ relative to saline but there were no other significant differences among the doses $(p s>.10)$. Similarly, the frequency of stretch attends was strikingly reduced at the $12.0 \mathrm{mg} / \mathrm{kg}$ dose relative to all other groups ( $p s<.05-.005)$, but with no

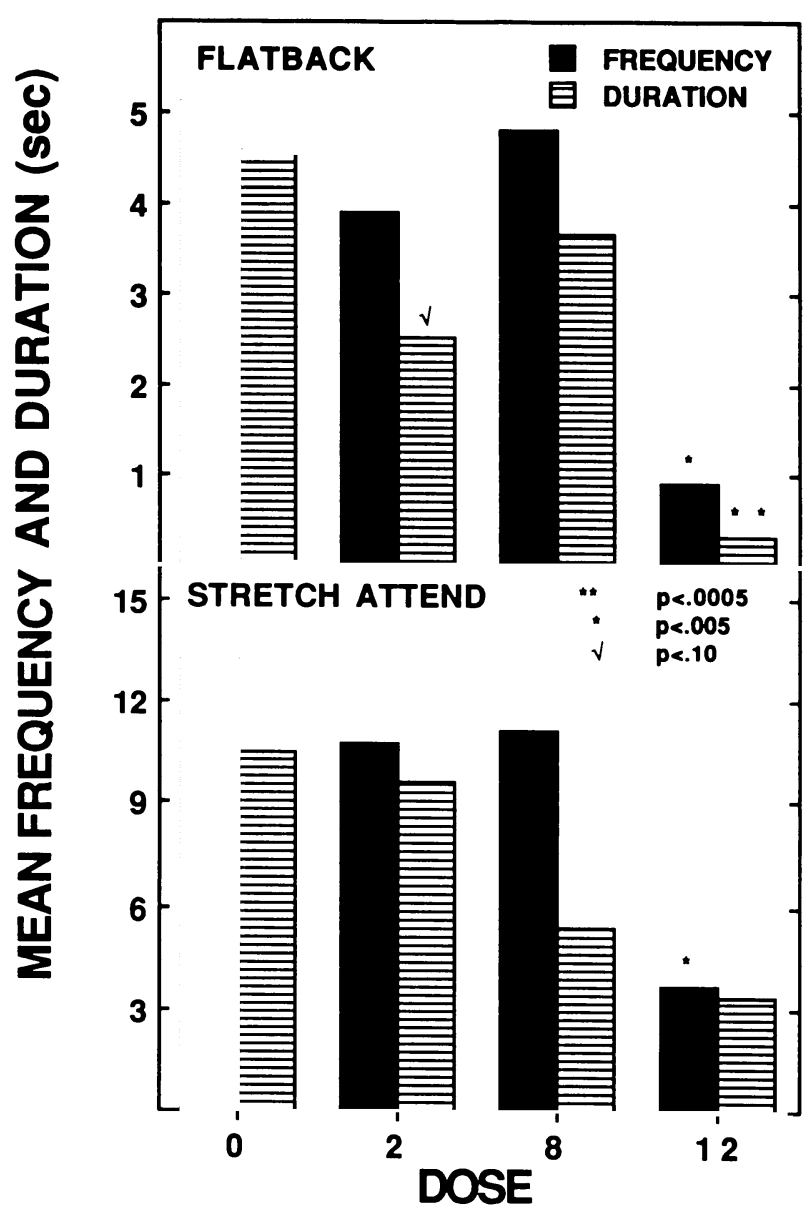

Figure 1. Mean frequency and duration of flatback approaches and stretch attends by groups receiving 0 (saline), 2.0, 8.0, and $12.0 \mathrm{mg} / \mathrm{kg}$ CDP treatments. reliable differences among the remaining groups ( $p s>$ .10). In addition, drug treatment produced a marginally significant overall increase in eating frequency $(H=6.42$, $p<.10)$ and duration $(H=6.51, p<.10)$, which seemed largely due to substantial increases in this measure at the $12.0 \mathrm{mg} / \mathrm{kg}$ dose. Drug treatment also produced a marginally significant increase in time spent in the odorous half of the aquarium $(H=6.68, p<.10)$. There were no reliable overall group differences in the frequency or duration of rearing or grooming (all ps > .10). The number of entries into the odorous half of the aquarium was also similar among all groups $(p>.10)$.

\section{DISCUSSION}

The strong suppression of risk assessment seen at the highest CDP dose is generally consistent with the suggestion that alterations in normal olfactory function contribute to the suppression of offensive attack by benzodiazepines (e.g., Dixon, 1982) and perhaps other drug classes as well (e.g., Kemble et al., 1986, 1991; Soffie \& Lamberty, 1988). Because the lower doses of CDP used in the present experiment are also known to reduce defensive threat and attack behavior (e.g., Blanchard et al., 1989), they might also have been expected to reduce levels of risk assessment as well. It should be noted, however, that CDP seems to have biphasic effects on agonistic behaviors (e.g., Rodgers \& Waters, 1985). At lower doses, CDP seems to consistently reduce defensive behaviors (e.g., Blanchard et al., 1989) but may actually increase attack behavior (e.g., Zwirner, Porsolt, \& Loew, 1975). Attenuation of attack behavior, in contrast, is most consistently observed at considerably higher doses (e.g., Krsiak, 1979). Thus, CDP-mediated shifts in olfactory function may be restricted to higher dose levels, which also suppress attack behavior. If so, the present results further suggest that the consistent suppression of defense, seen with lower CDP doses, is not mediated by altered olfactory activity.

\section{REFERENCES}

Blanchard, D. C., Blanchard, R. J., \& Rodgers, R. J. (1990). Pharmacological and neural control of anti-predator defense in the rat. Aggressive Behavior, 16, 165-175.

Blanchard, D. C., Hori, K., Rodgers, J. R., Hendrie, C. A., \& BLANCHARD, R. J. (1989). Attenuation of defensive threat and attack in wild rats (Rattus rattus) by benzodiazepines. Psychopharmacology, 97, 392-401.

Blanchard, R. J., \& BlanchaRd, D. C. (1990). An ethoexperimental analysis of defense, fear, and anxiety. In N. McNaughton \& G. Andrews (Eds.), Anxiety (pp. 124-133). Dunedin: University of Otago Press.

Blanchard, R. J., Blanchard, D. C., Weiss, S. M., \& Meyer, S. (1990). Effects of ethanol and diazepam on reactivity to predatory odors. Pharmacology, Biochemistry \& Behavior, 35, 775-780.

Dixon, A. K. (1982). A possible olfactory component in the effects of diazepam on social behavior of mice. Psychopharmacology, 77, 246-252.

File, S. E. (1990). The use of social interaction as a method for detecting anxiolytic activity of chlordiazepoxide-like drugs. Journal of Neuroscience Methods, 2, 219-238.

GARBE, C. M., \& KeMBle, E. D. (1993). Effects of prior agonistic experience on risk assessment and approach behavior induced by familiar or unfamiliar conspecific odors. Manuscript submitted for publication.

Garbe, C. M., Kemble, E. D., \& RAwleigh, J. M. (in press). Novel odors evoke risk assessment and suppress appetitive behaviors in mice. Aggressive Behavior.

Garbe, C. M., Rawleigh, J. M., Kemble, E. D., \& Bursell, A. L. (in press). No effects of chlordiazepoxide on reactivity to conspecific or novel odors. Psychological Record. 
Kemble, E. D., Behrens, M., Rawleigh, J. M., \& Gibson, B. M (1991). Effects of yohimbine on isolation-induced aggression, exploration, social attraction and olfactory preference. Pharmacology, Biochemistry \& Behavior, 40, 781-785.

Kemble, E. D., Schultz, L. A., \& Thornton, A. E. (1986). Effects of fluprazine hydrochloride on conspecific odor preferences in rats. Physiology \& Behavior, 37, 53-56.

KrSIAK, M. (1979). Effects of drugs on behaviour of aggressive mice. British Journal of Pharmacology, 65, 525-533.

Krsiak, M., \& Sulcova, A. (1990). Differential effects of six structurally related benzodiazepines on some ethological measures of timidity, aggression, and locomotion in mice. Psychopharmacology, 101, 396-402.

MiCZEK, K. A. (1974). Intraspecies aggression in rats: Effects of $d$-amphetamine and chlordiazepoxide. Psychopharmacologia, 39, 275-301.

Ostrem, J. L., Rawleigh, J. M., \& Kemble, E. D. (1992). Effects of eltoprazine hydrochloride on reactivity to conspecific or novel odors and activity. Pharmacology, Biochemistry \& Behavior, 41, 581 - 585.
PanksepP, J. (1971). Drugs and stimulus bound attack. Physiology \& Behavior, 6, 317-320.

Poole, T. B. (1973). Some studies on the influence of chlordiazepoxide on the social interaction of golden hamsters (Mesocricetus auratus). British Journal of Pharmacology, 48, 538-545.

RODGERS, R. J., \& WATERS, A. J. (1985). Benzodiazepines and their antagonists: A pharmacoethological analysis with particular reference to "aggression." Neuroscience \& Biobehavioral Reviews, 9, 21-35.

SOFFIE, M., \& LAMBERTY, Y. (1988). Scopolamine effects on juvenile recognition in rats: Possible interaction with olfactory sensitivity. $\mathrm{Be}$ havioural Processes, 17, 181-190.

Zwirner, P. P., Porsolt, R. D., \& LoEw, D. M. (1975). Intergroup aggression in mice: A new method for testing the effects of centrally active drugs. Psychopharmacologia, 45, 133-138.

(Manuscript received April 5, 1993.) 